\title{
Educação e economia solidária: uma análise das relações de participação e poder ${ }^{1}$
}

\author{
Telmo Adams ${ }^{2}$ \\ Fernanda Carvalho Ferreira ${ }^{3}$ \\ Joana Frank ${ }^{4}$ \\ Marina da Rocha ${ }^{5}$
}

\section{Resumo}

Este artigo constitui um dos focos de análise da pesquisa Educação popular e economia solidária: mediações entre formação ético-política e técnico-produtiva e visa sistematizar e problematizar a experiência do Centro de Formação em Economia Solidária (CFES/Sul), caracterizando os principais passos metodológicos desse programa. $\mathrm{O}$ foco de análise são as relações entre participação e poder. O referencial teórico baseou-se em Paulo Freire, Pierre Bourdieu, Cláudio Nascimento e outros. A problematização e análise ocorreram em dois âmbitos, no que concerne às relações de convencimento/manipulação, consulta/referendo e autogestão/deliberação democrática: a) na definição da política de educação em Ecosol - as relações entre o movimento de Ecosol e representantes do governo federal; b) nas atividades de formação do CFES/Sul - as relações de poder entre educadores e demais participantes. Graças ao amparo da proposta pedagógica, definida pelo movimento de Ecosol, a perspectiva autogestionária, apesar das contradições, manteve-se preponderante.

Palavras-Chave: educação; economia solidária; participação e poder; autogestão.

1 Artigo decorrente de pesquisa (2011-2013) que contou com apoio do CNPQ.

2 Doutor em Educação pela Universidade do Vale do Rio dos Sinos, UNISINOS, Brasil. Professor e pesquisador no Programa de Pós-Graduação em Educação na Universidade do Vale do Rio dos Sinos adams.telmo@gmail.com

3 Mestre em Educação na pela Universidade do Vale do Rio dos Sinos. Docente na Universidade Federal da Fronteira Sul. pronandacarvalho@gmail.com

4 Graduanda de Pedagogia pela Universidade do Vale do Rio dos Sinos. joana.frank@gmail.com 5 Graduanda de Pedagogia pela Universidade do Vale do Rio dos Sinos.

marina.darocha@hotmail.com 


\title{
Education and solidarity economy: an analysis of participation and power relations
}

\begin{abstract}
This article deals with one of the aspects analyzed in the study on "Popular education and solidarity economy: mediations between ethical-political and technical-productive education" and aims to systematize and discuss the experience of the Training Center for Solidarity Economy (CFES/South), featuring the main methodological steps of this program. The focus of analysis is the relation between participation and power. The theoretical reference was based on Paulo Freire, Pierre Bourdieu, Cláudio Nascimento and others. Problematization and analysis occurred in two spheres, in what concerns the relationship of persuasion/manipulation, consultation/referendum and self-management/democratic deliberation. There were considered: $a)$ in the definition of the policy of education in solidarity economy -, understood as an economic and social organization based on cooperation, within the relations between the movement of solidarity economy and representatives of the federal government; b) in the educational activities of CFES/sul - the power relations between educators and participants (workers, educators from organizations of the solidarity economy movement and supporting entities and public administrators). Thanks to the support of the pedagogical proposal defined previously by the solidarity economy movement, the self-management perspective continued to preponderate despite contradictions.
\end{abstract}

Keywords: education; solidarity economy; participation and power; self-management.

\section{Introdução}

As relações de participação e poder realizam-se em contextos sóciohistóricos determinados, dentro dos quais estão implicadas múltiplas variáveis. Para compreender essas relações no Brasil e América Latina, não podemos deixar de considerar as marcas das heranças coloniais que 
plasmaram uma cultura de silêncio, um $e^{2}{ }^{6}{ }^{6}$ de subserviência presente, em grande parte, na população empobrecida. Fatores econômicos e políticos destacam-se no conjunto de causas geradoras de desigualdades econômicas, dominações e dependências culturais que se estendem ao modo de existir individual e social. Destaca-se aqui a intrínseca relação entre "espaço e totalidade", em que a "formação social" apresentase como parte do modo de produção que "depende da distribuição quantitativa e qualitativa das infraestruturas e de outros atributos do espaço" (SANTOS, 2008, p. 32). Nessa perspectiva, o espaço social do colonialismo de vários séculos imprimiu modos de ser profundamente arraigados nas estruturas mentais, sociais e institucionais. Trata-se da colonialidade (QUIJANO, 2005; MIGNOLO, 2010) como herança do colonialismo, que, após as independências dos países latino-americanos e caribenhos, perpetuou-se na forma de matriz de relações verticais, centralizadoras e geradoras de subserviências e dominações.

Em tal conjuntura, compreende-se, pois, a secular exclusão política da maioria do povo brasileiro, cuja "história está repleta de vozes abafadas e de vidas sacrificadas em nome da fé, da ordem, do progresso e, mais recentemente, da governabilidade, da sustentabilidade ou da competitividade" (STRECK; ADAMS, 2006, p. 96). As formas de relações de participação e poder refletem esses condicionamentos incorporados nas pessoas e grupos, especificamente no caso desta pesquisa, educadores e sócios de empreendimentos de economia solidária.

O presente estudo foi realizado com os participantes das atividades desenvolvidas pelo Centro de Formação em Economia Solidária do Sul do Brasil (CFES/Sul), durante os anos de 2011 e 2012. O CFES/Sul foi implantado pela Secretaria Nacional de Economia Solidária, com outros quatro centros, nas demais regiões do país (Norte, Nordeste, Sudeste e Centro-Oeste), com a finalidade de realizar a formação de educadores, sistematizar experiências educativas, recriar metodologias de autogestão e organizar uma rede nacional de educadores.

$6 \mathrm{O}$ ethos equivale aos costumes, experiências, saberes e visões de mundo de cada sujeito que carrega as marcas da materialidade da vida construída na relação dialética entre objetividade e subjetividade caracterizando-se como uma matriz do modo cultural, de sabedoria implícita, da qual decorre um modo de compreender, de ser e agir no mundo (ADAMS, 2010). 
O método educativo proposto pelo CFES/Sul assume os princípios da educação popular com ênfase no processo participativo do educando e na valorização da atividade de trabalho, como mediação pedagógica para a aprendizagem. Os participantes eram trabalhadores e trabalhadoras de empreendimentos solidários, representantes de entidades de apoio e fomento e alguns representantes de governos que chamamos gestores públicos. O projeto político pedagógico enfatiza a potencialidade educadora do trabalho associado na economia solidária, destacando a experiência local com potencial estratégico para generalizar-se na sociedade (WIRTH; FRAGA; NOVAES, 2011).

A nossa participação começou como facilitadores/mediadores, em algumas atividades e como observadores em outras, tendo em conta a nossa opção pela pesquisa participante. Ao mesmo tempo, fomos tematizando questões teóricas para compreender como, naquele ambiente, ocorriam as relações entre participação e poder.

O método de pesquisa fundamentou-se em Fals Borda (1982; 2009), que desenvolveu a investigação-ação participativa com o intento de contribuir na identificação dos problemas pela própria população envolvida, proceder a análise crítica e construir coletivamente soluções adequadas à participação do pesquisador. A pesquisa participante desenvolvida no contexto de educação popular no Brasil tem sua marca na dimensão libertadora das relações de poder opressoras e estímulo a um processo participativo com radicalidade democrática (FREIRE, 1976; 1981:, 1994; BRANDÃO, 2003; 2006; BRANDÃO; STRECK, 2006; DEMO, 2008; FRANCO, 2005).

De acordo com Franco (2005), igualmente, a pesquisa-ação crítica desenvolve um trabalho inicial do pesquisador com o grupo mediante a valorização da construção cognitiva da experiência. Esse processo visa à emancipação dos sujeitos e à superação das condições que o grupo considera opressivas. Tal visão coincide com a pesquisa participante.

A pesquisa-ação crítica considera a voz do sujeito, sua perspectiva, seu sentido, mas não apenas para registro e posterior interpretação do pesquisador: a voz do sujeito fará parte da tessitura da metodologia da investigação [...] Daí a ênfase no caráter formativo dessa modalidade de pesquisa, pois o sujeito deve tomar 
consciência das transformações que vão ocorrendo em si próprio e no processo. É também por isso que tal metodologia assume um caráter emancipatório [...]. (FRANCO, 2005, p. 486).

Há, portanto, uma identidade entre pesquisa-ação crítica e a pesquisa participante na medida em que as duas produzem conhecimento politicamente engajado e emancipatório, sem abrir mão do rigor metodológico (DEMO, 2008). Com esse argumento, reafirmamos a estratégia pedagógica da metodologia participativa de pesquisa, porque essa tem em vista a construção coletiva de conhecimento por meio do estímulo a um processo educativo de interação entre todos os envolvidos.

Na parte inicial deste artigo, descrevemos e analisamos aspectos da dinâmica participativa e as relações de poder no processo de definição da política de educação em economia solidária, especificamente as relações entre o movimento de economia solidária e representantes do governo federal. Na segunda parte, o foco é a análise das relações de poder entre os membros do Comitê Metodológico ${ }^{7}$, por meio da observação das suas reuniões. Analisa, igualmente, as relações entre a equipe executiva e os participantes (trabalhadores, educadores de organizações do movimento de economia solidária e entidades de apoio e gestores públicos), que se dão nas atividades de formação do CFES/Sul. Ao final, segue a conclusão com considerações gerais da análise e alguns aspectos que identificamos como significativos.

\section{0 movimento brasileiro de economia solidária (ECOSOL) e a conquista de política pública de educação}

Como reação ao desemprego em massa na década de 1980, os movimentos sociais e os sindicatos de trabalhadores avaliaram que era insuficiente lutar contra o modelo de mercado neoliberal em implantação no Brasil (SINGER, 2003). Nesse contexto, surgiram inúmeras iniciativas de geração de trabalho e renda apoiadas por organizações

7 O Comitê Metodológico é composto pela equipe responsável pelo Programa em nome da instituição executora (três pessoas: um coordenador executivo, um coordenador pedagógico e um gestor administrativo), pessoas de universidades parceiras integrantes do projeto, de organizações não governamentais e do movimento de economia solidária. 
não governamentais, entidades religiosas e setores sindicais (ADAMS, 2010). No decorrer da década de 1990, o processo de articulação desses empreendimentos solidários e entidades de apoio resultou no movimento de economia solidária (ECOSOL). A sua articulação e proposição fortaleceu-se em 2001, durante o Fórum Social Mundial em Porto Alegre, Brasil. A realização da I Plenária Nacional da Economia Solidária, em 2002, definiu propostas de políticas públicas para ECOSOL, como contribuição ao programa de governo do então candidato à Presidência da República, Luiz Inácio Lula da Silva.

O processo participativo de amplos setores do país conquistou o que foi possível dentro das relações de poder estabelecidas entre movimento e gestores públicos: não um ministério, como desejava, porém, a criação da Secretaria Nacional de Economia Solidária (SENAES), órgão do Ministério do Trabalho e Emprego. Em seguida, com a participação de mais de 800 pessoas de 18 Estados brasileiros, a III Plenária Nacional (2003) criou o Fórum Brasileiro de Economia Solidária (FBES), organização representativa dos diversos atores/sujeitos da Economia Solidária no país. Este tem por finalidade articular e mobilizar o movimento de ECOSOL em torno de uma carta de princípios e uma plataforma de lutas, aprovada nessa plenária. Cada Estado passou a organizar igualmente seu fórum estadual de ECOSOL, constituído por representantes de empreendimentos solidários, entidades de apoio e gestores públicos. A partir desse órgão representativo, ocorreu o encaminhamento de políticas de educação com o objetivo de: a) realizar ações de formação com trabalhadores e trabalhadoras da economia popular solidária; b) articular e fomentar a rede de educadores/ formadores; c) ampliar o financiamento público a pesquisas e tecnologias para a melhoria da produção.

Como resultado da luta de diversos atores da economia solidária no Brasil, os Centros de Formação em Economia Solidária foram implantados, a partir de 2009, em cinco grandes regiões do país (Norte, Nordeste, Sudeste, Centro-Oeste e Sul, em 2010) e um Centro de âmbito nacional (Brasília). Sua finalidade era de articulação do todo, como um projeto de política pública da Secretaria Nacional de Economia Solidária (SENAES). Cada CFES, de acordo com o contexto regional, assumiu a 
tarefa de formação de educadores/formadores, a sistematização das experiências educativas e a disseminação de metodologias de educação popular, a experimentação da autogestão pedagógica e organização de uma rede nacional de educadores. Ou seja, as atividades desenvolvidas por cada CFES deveriam contribuir na preparação de educadores capazes de atuar em empreendimentos solidários e assim fortalecer o movimento como um todo, para assegurar formação integral (técnica e política) adequada às características organizacionais dos empreendimentos de economia solidária.

As tarefas do CFES/Sul foram implementar uma formação de educadores/formadores; sistematizar as experiências educativas; e disseminar metodologias de educação popular e autogestão pedagógica, oferecendo formação geral (dimensão ético-política) e assistência técnica adequada (dimensão técnico-produtiva) às características organizacionais dos empreendimentos e práticas de economia solidária.

O FBES coordenou a elaboração de propostas educativas para a economia solidária, em diálogo com a SENAES, cujos gestores públicos, em sua maioria, foram anteriormente militantes e apoiadores do movimento. Tal fato a princípio facilitou aproximações e a formulação de consensos em torno das propostas. Porém, o conflito se estabeleceu na correlação de força entre as estruturas internas de governo, especificamente o Ministério do Trabalho e Emprego, que manteve a ECOSOL restrita a um apêndice da política nacional de emprego e da formação profissional.

Assim sendo, permanecem os desafios da política de educação em economia solidária no contexto da atual organização estrutural do Estado brasileiro. A avaliação do processo participativo em andamento considera que houve significativas conquistas no decorrer do governo Lula, mas que não foram suficientes para tirar a economia solidária de um âmbito marginal em relação à economia hegemônica. E a expectativa de avançar na construção de uma política mais consistente resultou em sentimentos de retrocesso no que tange à concepção e ao projeto político da ECOSOL. Embora a participação dos diferentes atores do movimento tenha sido significativa, ela não resultou em fortalecimento de poder que incidisse 
na definição de políticas para a economia solidária no atual contexto brasileiro. Esse aspecto pode ser verificado, inclusive, no orçamento insignificante destinado ao desenvolvimento de ações educativas em todo o Brasil. Isso, possivelmente, tem a ver, com a lógica da burocracia do Estado brasileiro, em que tudo é visto sob a ótica mercantil e, portanto, não valoriza organizações socioeconômicas solidárias por serem insignificantes no PIB nacional. Como podem ser insignificantes os mais de dois milhões de trabalhadores envolvidos na ECOSOL no Brasil?

Todos esses aspectos ressaltam o desencontro entre a perspectiva pragmática, própria da lógica governamental no contexto de domínio das políticas neoliberais, de um lado, e a proposta política participativa de uma organização processual defendida pelo movimento de ECOSOL, de outro. Com isso, as estruturas - que teoricamente pretendem ser participativas e democráticas - tornam-se hierárquicas autoritárias, inibindo o empoderamento dos sujeitos e o fortalecimento da organização nos espaços da economia solidária.

O CFES não é uma escola convencional, mas, sim, um programa de política pública de formação viabilizada por meio de Convênios com o Estado Brasileiro. Entre os principais conteúdos a serem trabalhados, de acordo com o termo de referência, estavam alguns eixos temáticos orientadores: história e perspectivas do trabalho emancipatório nos rumos das transformações societárias; constituição e organização da ECOSOL; gestão dos Empreendimentos Econômicos Solidários (EES); processos de cooperação e comércio justo e solidário; marco jurídico da Economia Solidária; políticas públicas, participação cidadã e controle social, desenvolvimento local e territorial sustentável; outros temas e conteúdos de acordo com a demanda dos EES. Os educadores docentes convidados eram pessoas, em geral, preparadas não somente na compreensão dos conteúdos, mas, sobretudo, pela sua experiência em metodologia participativa/dialógica, diferente do método tradicional de transmissão de conhecimentos prontos. ${ }^{8}$

As atividades regionais (reunindo pessoas dos três estados brasileiros)

8 O número total de beneficiários: 729, sendo: 134 de Entidades de Apoio à Formação (EAF); 580 de Empreendimentos Econômicos Solidários (EES); e 15 pessoas de Gestões Públicas (GP). 
ocorriam em uma casa especializada para receber eventos em tempo integral. As atividades estaduais eram realizadas em algum local de fácil acesso em cada Estado. E as oficinas locais voltadas para as pessoas dos EES aconteciam nas diferentes regiões dos respectivos Estados, especialmente onde a organização da Economia Solidária estivesse mais consolidada.

\section{Participação e poder nas atividades do CEFs/sul}

A gestão do Projeto era coordenado por uma instituição juridicamente responsável pela administração financeira e gestão executiva das atividades do projeto. Para contemplar o processo participativo, o Projeto previu um Conselho Gestor ${ }^{9}$ responsável para traçar as diretrizes gerais no sentido de assumir corresponsavelmente os encaminhamentos necessários para o alcance dos objetivos, reunindo-se, regularmente a cada três meses.

Articulado com o Conselho Gestor havia o Comitê Metodológico, integrado por algumas pessoas das instituições parceiras, que tinham por incumbência definir os encaminhamentos metodológicos para as atividades em todos os níveis; e a Universidade executora (Unisinos Programa de Pós-Graduação em Ciências Sociais), com o sentido de uma extensão universitária. Nesta, propusemos uma pesquisa participante, ${ }^{10}$ que foi realizada ao longo dos dois anos, integrada como estratégia pedagogicamente estruturada para possibilitar a produção coletiva de conhecimentos, na medida em que proporciona aprendizagem com reciprocidade entre todos os que nela atuam. Tanto as atividades, como o método de pesquisa contemplaram aspectos centrais da participação, como sentir-se parte das tomadas de decisões, do planejamento, do desenvolvimento das atividades e da sistematização enquanto reflexão avaliativa sobre o processo realizado. Buscamos combinar a valorização dos saberes que os participantes já traziam com o aporte de novos

9 O Conselho Gestor é composto pela instituição executora, representantes de universidades e organizações da sociedade civil comprometidas com o projeto, uma representação dos Fóruns estaduais de economia solidária e de outros programas de políticas públicas como Brasil Local e Fundos Solidários. 10 Coordenada por Telmo Adams, a pesquisa teve o apoio direto de duas bolsistas de iniciação científica e a colaboração, na análise, do grupo de pesquisa mais amplo. 
conhecimentos, por meio da contribuição de educadores mais experientes convidados, ou também participantes membros de empreendimentos de ECOSOL. Vale registrar que, em nosso processo de pesquisa, ora nos sentíamos participantes, ora exercíamos o papel de pesquisador em diálogos organizados, alguns deles gravados e transcritos.

Em reuniões do Comitê metodológico, organizamos momentos de comunicação de resultados preliminares. Eram sempre oportunidades para agregar novos aspectos que passavam a integrar a continuidade de nosso trabalho, em questões como as incoerências entre o discurso de participação e autogestão nas atividades de formação do CFES/Sul; as contradições da prática autogestionária no cotidiano do trabalho. Ao mesmo tempo, os membros do Comitê manifestavam a importância da contribuição da equipe de pesquisa com a sistematização e a reflexão teórica, aspecto esse que estava previsto nos objetivos do CFES/Sul.

A prática educativa assumida pelo CFES/Sul propunha partir dos mesmos princípios da educação popular: levar em conta a realidade do "educando", valorizar o espaço de trabalho como ambiente de aprendizagem e agregar o conhecimento técnico-científico adequado ao projeto estratégico da economia solidária no Brasil, em sintonia com a economia social em outros países. Concebendo a educação como ato dialógico, problematizador, mediador, construtor de conhecimento coletivo e de caráter transformador da realidade social e individual, destacou-se a proposta metodológica da autogestão da pedagogia. As principais atividades consistiram em cursos de três a cinco dias, com duas ou mais etapas, além da formação realizada nos ambientes de trabalho (pedagogia da autogestão). O objetivo era valorizar o trabalho como princípio educativo, com ênfase na participação, corresponsabilidade e autonomia dos participantes.

Esse objetivo, porém, teve dificuldades para se viabilizar por falta de empreendimentos que se dispusessem a receber em seu espaço de trabalho, a diversidade de participantes. Entre os motivos alegados, estava a ideia de que a experiência não estava suficientemente desenvolvida para servir de referência educativa; ou se alegava a sobrecarga de trabalho, possivelmente receando a interferência de pessoas que viessem 
a atrapalhar o trabalho produtivo.

A perspectiva era estimular uma prática educativa emancipatória de fortalecimento da compreensão teórica a partir das práticas da autogestão, inclusive para aprender com as dificuldades enfrentadas nesse processo. Em teoria, a autogestão pressupõe relações de poder orientadas por um projeto comum, com participação ativa, igualitária e democrática de todos os participantes, em que o valor da participação como componente pedagógico ancora-se: no seu vínculo com igualdade e identidade em um determinado grupo humano; na relação entre participação e eficiência em vista de alcançar objetivos comuns; como prática de envolvimento que leva ao sentimento de pertença e autovalorização, contribuindo para formar sujeitos autônomos com um ethos de liderança democrática (STRECK; ADAMS, 2006).

A economia solidária, em alguns países chamada de economia social, constitui-se em espaço propício de educação popular, com ênfase na prática da autogestão, por meio de sua organização democrática e participativa com intencionalidade transformadora. Trata-se de um metódico e gradativo trabalho educativo em meio à organização de empreendimentos solidários como cooperativas populares, associações de produtores e consumidores, grupos de prestação de serviços diversos (serviços educacionais, de alimentação, de artesanato, fábricas recuperadas por trabalhadores etc.).

Em síntese, a potencialidade educadora da prática participativa na economia solidária está ligada à sua característica de experiência local, que, ao mesmo tempo, tem um potencial estratégico para generalizarse na sociedade (WIRTH; FRAGA; NOVAES, 2011). Nessa direção, a formação realizada no CFES tenciona ser uma proposta de "construção social". Os seus princípios, métodos e aprendizados almejam contemplar os sentidos da autogestão voltados para um novo desenvolvimento com sustentabilidade socioambiental. Nessa perspectiva, é por meio de relações de reciprocidade que se busca articular a prática democrática no local de trabalho com o processo de transformação social.

Para tanto, o CFES propõe, ainda, valorizar e promover o uso dos recursos da cultura e de saberes dos sócios de cooperativas ou da 
comunidade na qual elas estão inseridas. Busca, também, trabalhar as diversidades de linguagens e a transversalidade de temas, garantindo que os próprios trabalhadores e trabalhadoras possam ser também educadores capazes de articular conhecimentos científicos e saberes empíricos.

No CFES/Sul, as atividades de formação realizadas com trabalhadores e trabalhadoras de empreendimentos solidários, representantes de entidades de apoio ou de fomento e gestores públicos foram preparadas pela equipe executiva após discussão de possibilidades no comitê metodológico. Desse comitê, semelhante à composição do Conselho Gestor, participavam representantes de universidades parceiras, de organizações não governamentais e do movimento de ECOSOL. O ponto de partida era o que previa o projeto básico aprovado pelo já citado órgão do governo federal, o que impunha alguns limites na forma de encaminhamento das atividades.

Contudo, para ser coerente com o trabalho associado nas cooperativas e associações de trabalhadores e trabalhadoras, a equipe executiva, com apoio do comitê metodológico, buscou garantir a proposta de autogestão, por meio da indicação de um caminho básico para os cursos de cinco dias e outros eventos de formação. Para tanto, propôs uma dinâmica coletiva de construção indutiva e processual.

Nascimento (2011) destaca que "As experimentações de autogestão mobilizam os trabalhadores para uma tarefa concreta e, assim, adquirem no processo e modo indutivo uma formação para autogestão" (p. 117). Com essa compreensão, o autor pressupõe que o agir democrático, um dos elementos centrais no processo autogestionário, não se aprende teoricamente. Daí a insistência de Freire (1976), sempre atual: “Se há saber que só se incorpora ao homem experimentalmente, existencialmente, este é o saber democrático" (p. 92). O mesmo pode ser afirmado em relação ao saber da autogestão. Identificada também como uma prática de educação popular no espaço econômico, em que ação e mundo estão dialeticamente relacionados, não faz dicotomia entre ação e reflexão. A educação popular pode ser compreendida como diálogo de saberes que constrói conhecimento e amplia o universo de sentido dos sujeitos envolvidos. Esse diálogo possibilita trilhar o caminho de uma concepção 
dialética em que se reconheçam determinações ou condicionamentos mútuos: das estruturas econômicas na conformação das subjetividades sociais, e vice-versa, dos sujeitos individuais e coletivos incidindo na realidade na qual estão inseridos para transformá-la.

No CFES, a prática metodológica da educação popular apresentou diversas dificuldades e contradições no seu desenvolvimento. Apesar de um razoável número de pessoas que acompanharam a discussão e elaboração do Projeto do CFES/Sul, a maioria dos inscritos nos cursos não havia participado do processo. Daí que a proposta de autogestão pedagógica tenha gerado surpresa e até rejeição. Segundo depoimentos colhidos, era visível o "susto inicial" como observa uma representante ${ }^{11}$ de um empreendimento de economia solidária:

Houve um choque inicial frente à expectativa de receber conteúdo versus a proposta de construção coletiva de conhecimento (autogestão da pedagogia). Porque a gente vem condicionado nessa cultura, com o professor lá na frente e a gente aqui, só esperando para receber o conhecimento. Quando a gente se deparou com o CFES, a gente se assustou, porque é completamente diferente. Mas à medida que a gente foi conhecendo a proposta $\mathrm{e}$ foi valorizando os nossos saberes, acho que a gente foi entrando na mesma e sentiu o efeito. (Katiucia da Silva).

Havia muitas resistências junto com um sentimento de insegurança. Os participantes esperavam um programa pré-definido, com professores para ensinar. A metodologia autogestionária, da maneira como estava sendo praticada, significava perda de tempo para algumas pessoas. Em uma das avaliações, que ocorriam regularmente, provocadas pela equipe executiva do CFES/Sul, alguém considerou que ocorreram definições e encaminhamentos sem planejamento e que a metodologia autogestionária não significa improvisação. Para evitar tais interpretações, sugeriu-se que as atividades fossem preparadas com maior tempo de antecedência para que todos os participantes possam sintonizar com os objetivos pretendidos.

Alguns participantes desse curso regional, que conosco analisaram essa postura de rejeição à metodologia autogestionária, testemunham 
que aquelas pessoas, ao desenvolverem o trabalho formativo em sua região, faziam-no de forma tradicional, por meio da transmissão de conteúdos, reproduzindo as relações em que o educador detém o poder do conhecimento e impede a construção coletiva de saberes. É o que podemos ver no depoimento que segue:

[...] eu percebo que é uma dificuldade enorme, inclusive dos educadores, de perceberem e de vivenciarem a pedagogia da autogestão, [...] porque, normalmente, quando os formadores vão para o trabalho de formação, eles levam um planejamento todo pronto. Eles não conseguem deixar com que o próprio empreendimento trabalhe suas questões [...]. Eles acabam quase que impondo uma metodologia, não sabendo conduzir essa autogestão, justamente por uma questão de insegurança. (Adalberto Sabino) ${ }^{12}$.

Do depoimento desse educador, podemos questionar se a formação realizada pelo CFES/Sul é suficiente para que os participantes incorporem um novo ethos metodológico de trabalho?

Entre os diferentes aspectos que merecem ser aprofundados na análise, focaremos a problematização sobre as condições de participação em que se encontram os diversos sujeitos envolvidos na dinâmica do programa desenvolvido pelo CFES/Sul. É necessário observar que os princípios da autogestão não são compatíveis com a rigidez das regras e condições dos programas financiados com recursos governamentais, estabelecidas, muitas vezes, em função de metas quantitativas que exigem uma execução pragmática do programa de política pública dentro de prazos exíguos. Isso condiciona e, em certo sentido, limita as possibilidades de relações participativas que contemplem o envolvimento dos sujeitos do planejamento, execução e avaliação dos resultados do programa.

Outro aspecto refere-se às condições da participação dos sujeitos que têm a ver com sua história, qualidade de sua experiência de vida e educação (inclusive a escolarização), com sua capacidade argumentativa, sua maturidade emocional, psicológica e liberdade para assumir posições autônomas. Isso depende da visão de mundo de cada indivíduo e grupo em Porto Alegre. 
social, a qual se constrói a partir da sua posição no espaço social. Essas condições individuais e sociais exercem uma influência direta no tipo de participação e nas relações de poder. Como exemplifica Tatiana, ${ }^{13}$ membro da equipe executiva:

Acho que é um conjunto de fatores. É o acúmulo pessoal de conhecimento, de trabalho comunitário, pois eu lembro de algumas pessoas, independente da escolaridade, que vieram com muito acúmulo de experiência do movimento de mulheres camponesas, de comunidades de base. (Tatiana Hausen).

Se a experiência anterior não ocorreu dentro dos princípios da participação democrática, facilmente o resultado será a concentração do poder decisório nas mãos de pequenos grupos. Isso ocorre porque os demais participantes não possuem os recursos e habilidades para contrapor-se àquela forma de poder (WEYH, 2011).

No contexto de heranças da colonialidade, que se manifestam por relações de subserviência e dominação, ou mesmo em uma cultura de silêncio, compreendemos o poder como uma relação, uma "ordenação intrínseca de um ser em direção a outro" (GUARESCHI, 2008, p. 141142), que pode ser de complementaridade ou de dominação. Assim o exercício do poder implica em relações sociais em que os grupos humanos se mantêm como estão ou se transformam por meio de interações, e não simplesmente por posturas individuais. Essas relações de poder são assimétricas quando alguém tem a capacidade de determinar o comportamento de outros, dependendo de fatores de participação, como conhecimento, habilidades, atitudes e recursos (SCHUGURENSKY, 2005). Destacamos também a habilidade pessoal de manejar e converter recursos à sua disposição em função dos próprios interesses e motivações. Nesse sentido, observando os processos das atividades do CFES/Sul, compreendemos que a participação gira em torno de três tipos de relações: manipulação/convencimento, consulta/referendo e autogestão/deliberação.

Inicialmente, denominamos por "manipulação/convencimento" o tipo de relações determinado pela postura diretiva dos gestores da 
instituição promotora, quando esta busca obter o apoio aos conteúdos e modo de abordagem pré-definidos. Realiza uma intervenção argumentativa para convencer os participantes que não têm possibilidade de influenciar ou modificar a opção apresentada e que, por estar definida em convênio, deve ser posta em prática.

A análise considera essas relações presentes nos participantes dos cursos e encontros. A primeira turma era constituída por um grande número de lideranças, as quais denominamos educadores, em função da sua prolongada experiência e razoável capacidade de compreensão e argumentação em torno das temáticas em questão. Esses educadores tinham mais de cinco anos de participação na ECOSOL. Porém, nas atividades seguintes, tanto em cursos, como em oficinas, ficou visível a rotatividade de pessoas. O critério de escolha passara a ser a disponibilidade de permanecer na turma até a conclusão das três etapas. Com isso, passaram a integrar o curso muitas pessoas iniciantes. Essa mudança no perfil dos participantes dificultou uma experimentação mais aprofundada da autogestão da pedagogia. Em decorrência, o resultado inicialmente esperado não ocorreu, abrindo caminho para as práticas de manipulação/convencimento.

O coordenador pedagógico, membro da equipe executiva do CFES/Sul, assumia a incumbência de apresentar a proposta metodológica. Os trabalhos eram introduzidos por meio da explicitação dos objetivos e da proposta do caminho participativo a ser trilhado. Após a concordância ou silêncio dos participantes, na fase inicial das atividades, organizavam-se equipes autogestionárias: criatividade, memória, cuidados, avaliação e coordenação.

Em algumas equipes autogestionárias, a postura de persuasão não era visível. Porém, na equipe de coordenação, esse tipo de relação evidenciava-se, sobretudo quando alguma liderança mais experiente, ao levantar alguma discordância, gerava tensões e dificuldades para encontrar o encaminhamento mais adequado e de consenso. Contudo, como havia um acordo em torno do caminho projetado, com base no regramento do convênio com o governo federal, a prática autogestionária ficava submissa ao planejamento. "No CFES as atividades já estavam definidas, as atividades com seu público, com a sua carga horária, 
inclusive com o tipo de conteúdo que estavam indicados [...] (José Inácio Konzen)" ${ }^{14}$ Para além da equipe autogestionária de coordenação, as relações de poder, no contexto do Curso Regional de cinco dias, estabeleciam-se entre os membros da equipe executiva, responsáveis pelo desenvolvimento do projeto em nome da instituição executora, e os demais participantes - líderes de empreendimentos solidários, educadores de instituições de apoio e membros de administrações públicas que atuam com economia solidária.

O segundo tipo de relação, a "consulta/referendo", caracterizase por um diálogo informativo que possibilita ouvir os interesses ou necessidades dos participantes, podendo levar a instituição responsável (equipe executiva) a realizar ajustes ou mudanças no conteúdo e no modo de desenvolvê-lo. Auscultam-se as necessidades que os participantes manifestam para contemplá-las nos objetivos e método de trabalho, contudo, sem abrir mão do poder de decisão, que fica sob responsabilidade da instituição conveniada. Este nível de participação pode contemplar a presença de representantes do grupo social em comitês de poder decisório, exercendo alguma influência nas decisões ou apenas referendando-as em outras instâncias.

Visivelmente, considerando o trabalho do conjunto das equipes autogestionárias, a tarefa mais difícil estava sob a responsabilidade da coordenação, que era integrada por alguém da equipe executiva do CFES e do Comitê metodológico, além de representantes dos participantes que se ofereciam para contribuir. Apesar dos momentos de diálogo, em que os participantes podiam opinar, não ocorreram significativas mudanças nas formas de encaminhamento das atividades. Algum membro de empreendimento que integrava a coordenação, em muitos casos, atuava como mero executor de alguma tarefa na condução do encontro. $O$ fato de todos os participantes integrarem uma equipe autogestionária criava um clima de aceitação do que cada uma delas propunha para todos. A maioria dos encaminhamentos era referendada, num clima de cumplicidade, mas por vezes também com certa indiferença ou desinteresse.

14 Entrevista concedida por José Inácio Konzen no dia 11 de junho de 2013 - coordenador do segundo programa do CFES/Sul iniciado no corrente ano. 
Por último, outro tipo de participação caracteriza-se pela prática da "autogestão/deliberação democrática". Nela, ocorre a divisão do poder de maneira corresponsável entre os membros participantes e representativos de todas as organizações que integram o programa e equipe executora do projeto. A tomada de decisões ocorre no coletivo por consenso ou, em certos casos, pelo voto argumentado.

No decorrer dos cursos, as equipes autogestionárias tinham liberdade para planejar da forma como avaliassem mais conveniente, tendo em vista fortalecer a participação autogestionária. Observamos, assim, por vezes, um clima de participação e experimentação coletiva que se instaurava como um processo indutivo de formação. Porém, ao mesmo tempo, algumas contradições e conflitos revelavam práticas consultivas, de convencimento ou manipulação. Essas contradições e conflitos revelam o peso do capital simbólico da instituição executora, amparada pela relação com o governo federal e capital político dos gestores cuja posição não era contestada pelos demais membros. Bourdieu (1989) define o capital político como capacidade/habilidade de influenciar decisões políticas (SCHUGURENSKY, 2005; WEYH, 2011; WERLE, 2003).

Segundo Werle (2003), as condições desiguais entre os sujeitos envolvidos resultam de um leque de disparidades que repercutem nas relações de poder. Para a autora, "As disparidades culturais entre os indivíduos podem ser um importante fator de favorecimento de certos grupos que exercem poder sobre os demais pela sua habilidade na formulação de temas e manipulação de alternativas." (WERLE, 2003, p. 79).

A habilidade de manejar recursos pessoais num contexto complexo de relações ocorre pela mediação da linguagem, que é sempre intencional, portanto não neutra; linguagem esta utilizada pelos sujeitos para expressar o seu pensamento. Este "está presente em sua totalidade e num só momento, mas na fala tem que ser desenvolvido em uma sequência" (VYGOTSKY, 1987, p. 129), sem que seja uma transição direta do pensado.

Como recursos que interferem no nível da habilidade, devem ser mencionadas ainda as ferramentas técnicas, como a rede de internet, capazes de potencializar informações utilizadas em argumentos a favor ou contra determinada proposta em questão. Enquanto alguns 
participantes, especialmente representantes de instituições de apoio, estavam conectados e, por isso, tinham um leque de informações à sua disposição, outros permaneciam como ouvintes, dizendo a sua palavra apenas em momentos de subgrupos por estarem "desapossados de instrumentos materiais e culturais necessários à participação ativa [...]" (BOURDIEU, 1989, p. 164).

O fato é que, quanto mais baixo o nível de mobilização dos aspectos mencionados, maior o desafio de suscitar um processo participativo e de poder partilhado de maneira autogestionária, especialmente quando se trata de pessoas marcadas pelas heranças de dominação ou opressão, acostumadas a seguir prescrições. Na compreensão de Freire (1978), um dos elementos básicos da relação de dominação é a prescrição.

Daí, o sentido alienador das prescrições que transformam a consciência recebedora no que vimos chamando de consciência "hospedeira" da consciência opressora. [...] Os oprimidos, que introjetam a "sombra" dos opressores e seguem suas pautas, temem a liberdade, na medida em que esta, implicando na expulsão desta sombra, exigiria deles que o "preenchessem" o "vazio" deixado pela expulsão, com outro "conteúdo" - o de sua autonomia. O de sua responsabilidade, sem o que não seriam livres (p. 35).

A ausência de autonomia para mobilizar recursos no ato de participar das decisões exige, em geral, um longo processo de reeducação das pessoas. Para que tal processo concretize-se, é necessária a mediação de políticas públicas emancipadoras que ofereçam oportunidades objetivas, como trabalho, educação e conquista de outros direitos humanos fundamentais.

Em síntese, a participação e o poder dos indivíduos, de um lado, é diretamente proporcional à posse e utilização de instrumentos materiais e culturais juntamente com a capacidade de argumentação. De outro lado, é decisiva a presença do capital simbólico, que age como força política no processo decisório. Em muitos casos, determinados participantes concordavam com os argumentos dos que dispunham de melhores "instrumentos". Desse modo, delegavam a sua participação por abstenção ou "desapossamento", favorecendo, assim, o domínio dos profissionais mais experientes na área em questão, especialmente pelo conhecimento apropriado e mobilizado em favor da argumentação defendida. 
No entanto, pelas posições dos gestores do projeto do CFES/Sul, é importante notar que a manipulação/convencimento não buscou impedir, mas, ao contrário, estimular a participação. A ênfase foi garantir que o processo autogestionário ocorresse sem deixar de cumprir as regras descritas no convênio, que condicionaram o modo de agir dos gestores da instituição. De outra parte, permanece a necessidade de ouvir e atender as demandas dos empreendimentos solidários. Tais demandas, por vezes, solicitam a formação na dimensão ético-política; em outros casos, correspondem a necessidades de ordem técnico-produtiva. O desafio é evitar a dicotomia e potencializar a mediação dinâmica entre estas duas dimensões intrínsecas de uma educação autogestionária.

\section{Conclusão}

Em relação às atividades do CFES/Sul, destacamos a heterogeneidade de fatores que influenciam a qualidade da participação. Mesmo que o ser humano seja dotado de uma vontade ontológica de participação, ele é socializado num contexto sociocultural que condiciona o seu ser, o seu pensar e o seu agir. Em outras palavras, o ethos dos participantes, de forma muito variada, compõe a qualidade do capital político, o qual complexifica os desafios da prática da autogestão, como verificamos no decorrer das atividades do CFES/Sul. No ambiente da economia solidária, o poder é igualmente mediado por disputa de interesses (contradições), paralelamente às práticas de cooperação (complementaridades) e reciprocidade que se desenvolvem em torno de consensos ou objetivos comuns.

Os três tipos de relações de participação e poder descritos neste texto foram os parâmetros da nossa análise compreensível. Com um olhar complexo, buscamos contemplar as influências múltiplas sobre as relações sociais, sobretudo as exercidas por fatores vinculados a desigualdades de gênero, etnia, cultura e classe social, no contexto das disparidades econômicas e sociais e, de modo especial hoje, as condições de acesso aos meios tecnológicos. Compreendemos que esses fatores incidem diretamente na capacidade de participar ativamente na tomada de decisões.

Entretanto, é preciso destacar que, apesar desse limite, a proposta 
de uma pedagogia participativa estava contemplada no projeto. A dificuldade aparecia, de maneira explícita ou velada, entre os participantes dos cursos que não participaram da discussão e elaboração do projeto e, portanto, não o conheciam e apresentavam expectativas e interesses distintos. Em decorrência, tiveram dificuldade de assimilar a proposta de uma metodologia participativa na perspectiva da autogestão. Uma educadora ${ }^{15}$ do comitê metodológico analisou que havia sempre divisões no grupo: de um lado, os que tinham uma expectativa acadêmica - por exemplo, trabalhar com artigos, autores e aprofundar temas teóricos -, enquanto outra parte do grupo, sintonizada com o projeto em execução, defendia assumir, em todos os momentos, uma postura coerente entre os princípios de participação, de acordo com o que se buscava viver no espaço de trabalho da economia solidária, isto é, a prática da autogestão.

Um tensionamento que perpassou o conjunto do programa de formação foi a dificuldade de estabelecer uma mediação entre as dimensões ético-política (as relações, os princípios e projeto da economia solidária) e técnico-produtiva (gestão da produção, administração, finanças e comercialização). Os conteúdos tiveram sua ênfase maior na primeira dimensão, defendida predominantemente pelas instituições apoiadoras, em detrimento da segunda, com presença forte nas expectativas dos empreendimentos de economia solidária. A avaliação de um educador ${ }^{16}$ considerou que, em função do sentido político transformador que se quer com a economia solidária e frente às dificuldades de modificar os objetivos pré-definidos, as demandas técnico-produtivas apresentadas pelos participantes dos empreendimentos não puderam ser contempladas. Mas ele entende que tais demandas devam ser atendidas na continuidade por serem autênticas e necessárias.

Averiguamos, nas atividades do CFES/Sul, a presença maior ou menor das três relações de convencimento/manipulação, consulta/ referendo e autogestão/deliberação democrática. As relações de

15 Isabel Lima participante do Comitê metodológico do CFES/Sul representando o coletivo de educadores e educadoras do Rio Grande do Sul. Entrevista concedida em 27.07.2012.

16 Depoimento de Fernando Zamban, membro do Comitê Metodológico, representante das instituições de apoio à economia solidária, pelo Estado de Santa Catarina. Entrevista concedida em 28.06.2012. 
consulta/referendo e, em alguns casos, de práticas de manipulação e convencimento ligam-se ao compromisso assumido pela instituição legalmente responsável pela execução do projeto.

Graças ao amparo da proposta pedagógica construída anteriormente pelo movimento de economia solidária, a perspectiva autogestionária possibilitou um processo de mudanças de mentalidades e de corações, alcançando resultados que se multiplicaram nos espaços locais, especialmente em empreendimentos, fóruns municipais e regionais de economia solidária. Apesar da ênfase na dimensão ético-política, que contemplou as relações humanas e a intercomunicação, alguns depoimentos de participantes de empreendimentos reconhecem que o CFES lhes deu mais segurança para trabalhar e atuar como educadores. A experiência de trabalho autogestionário possibilitou uma compreensão e postura mais autônoma, fazendo com que tivessem coragem para realizar processos formativos com outros empreendimentos, bem como junto aos fóruns de economia solidária. ${ }^{17}$ "Para mim era tudo novo [...] mas agora eu já sei contribuir com os outros", disse uma educadora, membro de um empreendimento na região oeste do Paraná. Na mesma perspectiva, o depoimento de um educador sobre uma participante de Blumenau, Santa Catarina, destaca o seu crescimento no decorrer da experiência no CFES/sul:

Eu me recordo sempre da Dona Laíde, de Blumenau. Uma senhora fantástica que, com todos os limites, traz uma sabedoria infinita. Lembro que, no primeiro contato que tive com ela, ainda assustada com o que estava acontecendo, agradeceu a oportunidade de participar. Na última, já estava resolvendo conflitos na equipe de sistematização. Ficou evidente pra mim que o processo do CFES contribuiu com a metodologia de atuação da Dona Laíde, não apenas no aspecto formativo, mas pessoal. (Sueli da Silva)

A possibilidade de estar no curso do CFES/Sul oportunizou a Laíde superar certas disparidades culturais, apropriar-se e construir conhecimentos articulados com os saberes que ela já detinha, além de aprender habilidades para dizer a sua palavra, a fim de posicionar-se

17 Depoimento de Sueli da Silva, mulher negra, membro de um empreendimento solidário e representante do Fórum de Economia Solidária de São Leopoldo (fonte: vídeo "Formação de educadoras e educadores em economia solidária - CFES/Sul-RS"). 
com mais autonomia frente ao grupo que inicialmente a inibia. Assim, diversos testemunhos mostram a validade do processo de educação autogestionária proposto. Inicialmente assustou, mas depois os participantes, de alguma forma, apropriaram-se da dinâmica indutiva de formação mediada pela participação.

Quanto às relações de participação e poder no processo de construção de uma política pública de educação em economia solidária, concluímos que o CFES representa o que foi possível conseguir como resultado da negociação com o governo federal, por meio do órgão responsável, a Secretaria Nacional de Economia Solidária do Ministério do Trabalho e Emprego (SENAES/MTE). 


\section{Referências}

ADAMS, T. Educação e economia popular solidária. Aparecida, SP: Ideias \& Letras, 2010.

BOURDIEU, P. O poder simbólico. Tradução Fernando Tomaz. Lisboa: DIFEL, 1989.

BRANDÃO, C. R. A pergunta a várias mãos: a experiência da pesquisa no trabalho do educador. São Paulo: Cortez, 2003 (Série saber com o outro, v. 1).

BRANDÃO, C. R. A pesquisa participante e a participação da pesquisa: Um olhar entre tempos e espaços a partir da América Latina. In: BRANDÃO, C. R; STRECK, D. R. (Orgs.). Pesquisa Participante: O saber da partilha. Aparecida, SP: Ideias e Letras, 2006. p. 21-54.

BRANDÃO, C. R.; STRECK, D. R. (Orgs.). Pesquisa participante: O saber da partilha. Aparecida, SP: Ideias e Letras, 2006.

DEMO, P. Pesquisa Participante. Saber pensar e intervir juntos. 2. ed. Brasília: Líber Livro, 2008 (Série Pesquisa, v. 8).

FRANCO, M. A. S. Pedagogia da pesquisa-ação. Educação e Pesquisa, São Paulo, v. 31, n. 3, p. 483-502, set./dez. 2005.

FREIRE, P. Educação como prática da liberdade. 6. ed. Rio de Janeiro: Paz e Terra, 1976.

FREIRE, P. Pedagogia do oprimido. 10. ed. Rio de Janeiro: Paz e Terra, 1981.

FREIRE, P. Pedagogia da esperança. Um reencontro com a Pedagogia do Oprimido. 3. ed. São Paulo: Paz e Terra, 1994. 
FALS BORDA, O. Aspectos teóricos da pesquisa participante. In: BRANDÃO, C. R. (Org.). Pesquisa participante. São Paulo: Brasiliense, 1982. p. 92-111.

FALS BORDA, O. Una sociología sentipensante para América Latina: antología y presentación de Víctor Manuel Moncayo. Bogotá: Siglo Del Hombre Editores y Clacso, 2009.

GUARESCHI, P. A. Pressupostos psicossociais da exclusão: competitividade e culpabilização. In: SAWAIA, B. (Org.). As artimanhas da exclusão. Análise psicossocial e ética da desigualdade social. 8. ed. Petrópolis, RJ: Vozes, 2008. p. 141-156.

MIGNOLO, W. D. Desobediencia epistémica: retórica de la modernidad, lógica de la colonialidad y gramática de la descolonialidad. Buenos Aires: Del Signo, 2010.

NASCIMENTO, C. Experimentação/Autogestionária: autogestão da pedagogia/ pedagogia da autogestão. In: BATISTA, E. L; NOVAES, H. (Orgs.). Trabalho, educação e reprodução social. As contradições do capital no século XXI. Bauru, SP: Canal 6 Editora, 2011. p. 107-132.

QUIJANO, A. Colonialidade do poder, eurocentrismo e América Latina. In: LANDER, E. (Org.). A Colonialidade do saber. Eurocentrismo e ciências sociais, perspectivas latino-americanas. Buenos Aires: CLACSO, 2005. p. 227-278.

SANTOS, M. Da totalidade ao lugar. São Paulo: EdUSP, 2008.

STRECK, D. R.; ADAMS, T. Lugares da participação e formação da cidadania. Civitas - Revista de Ciências Sociais, Porto Alegre, v. 6, n. 1, p. 95-117, 2006.

SINGER, P. Economia solidária: um modo de produção e distribuição. 
In: SINGER, P; SOUZA, André Ricardo de (Orgs.). A economia solidária no Brasil - autogestão como resposta ao desemprego. São Paulo: Contexto, 2003. p. 36-54.

SCHUGURENSKY, D. Aprendizado para a cidadania e engajamento democrático: o capital político revisitado. In: STRECK, Danilo et al. (Orgs.). Dizer a sua palavra. Educação cidadã, Pesquisa Participante e Orçamento Público. Pelotas, RS: Seiva, 2005. p. 141-158.

VYGOTSKY, L.S. Pensamento e linguagem. São Paulo: Martins Fontes, 1987.

WERLE, F. O. C. Conselhos escolares: implicações na gestão da Escola Básica. Rio de janeiro: DP\&A, 2003.

WEYH, C. B. Educar pela participação: uma leitura político-pedagógica do Orçamento Participativo Estadual no município de Salvador das Missões-RS. Santo Ângelo, RS: URI, 2011.

WIRTH, I. G.; FRAGA, L; NOVAES, H. T. Educação, Trabalho e Autogestão: limites e possibilidades da economia solidária. In: BATISTA, E. L; NOVAES, H. (Orgs.). Trabalho, educação e reprodução social. As contradições do capital no século XXI. Bauru, SP: Canal 6 Editora, 2011. p. 191-218. 